\title{
A multifunctional battery module design for electric vehicle
}

\author{
Meng Wang ${ }^{1} \cdot$ Liangliang $\mathrm{Zhu}^{2} \cdot$ Anh V. Le ${ }^{1} \cdot$ Daniel J. Noelle ${ }^{3} \cdot$ Yang Shi $^{3}$. \\ Ying Zhong ${ }^{3}$ Feng $\mathrm{Hao}^{2} \cdot \mathrm{Xi}_{\mathrm{Chen}^{2}} \cdot \mathrm{Yu}_{\mathrm{Qiao}}{ }^{1,3}{ }_{(\mathbb{C}}$
}

Received: 5 May 2017/Revised: 11 September 2017/ Accepted: 19 September 2017/Published online: 6 November 2017

(c) The Author(s) 2017. This article is an open access publication

\begin{abstract}
Reducing the overall vehicle weight is an efficient, system-level approach to increase the drive range of electric vehicle, for which structural parts in auto-frame may be replaced by battery modules. Such battery modules must be structurally functional, e.g., energy absorbing, while the battery cells are not necessarily loading-carrying. We designed and tested a butterfly-shaped battery module of prismatic cells, which could self-unfold when subjected to a compressive loading. Angle guides and frictionless joints were employed to facilitate the large deformation. Desired resistance to external loading was offered by additional energy absorption elements. The battery-module behavior and the battery-cell performance were controlled separately. Numerical simulation verified the experimental results.
\end{abstract}

Keywords Electric vehicle - Battery module ·

Multifunctional · Energy absorption

\section{Introduction}

While the first electric vehicle (EV) was developed a few decades ago [1], there are still a large number of technical hurdles that must be overcome, before EVs can be widely

Yu Qiao

yqiao@ucsd.edu

1 Department of Structural Engineering, University of California - San Diego, La Jolla, CA 92093-0085, USA

2 Columbia Nanomechanics Research Center, Department of Earth and Environmental Engineering, Columbia University, New York, NY 10027, USA

3 Program of Materials Science and Engineering, University of California - San Diego, La Jolla, CA 92093, USA commercialized. One key issue is the drive range: To compete with fossil-fuel vehicles, once being charged, an EV should be able to travel 200-300 miles, for which $70-80 \mathrm{~kW} \mathrm{~h}$ electrical energy is needed [2]. Thus, the battery system in an EV, including battery cells and pack components, could be heavier than $500 \mathrm{~kg}$ [3].

It was suggested that the specific energy of EV battery system must be more than $\sim 150 \mathrm{Wh} / \mathrm{kg}$ at the pack level [4]. A promising way to achieve this goal is to render the battery modules/packs multifunctional. For instance, they can be energy absorbing and protective. As a first-order approximation, assume the mass of a lightweight EV is $M=1000 \mathrm{~kg}$. At the speed of $v=35 \mathrm{MPH}$-the vehicle speed in standard crashworthiness testing [5], the EV would carry a kinetic energy of $K=120 \mathrm{~kJ}$. The volume of an EV battery system is $V=300 \mathrm{~L}$ [6]. If upon collision the battery system volume could shrink by $\sim 50 \%$, the kinetic energy can be entirely dissipated as long as the crushing pressure $(P)$ is above $0.8 \mathrm{MPa}$. Disintegration of battery pack under this condition is acceptable, since the EV structure has been destroyed.

For another order-of-magnitude assessment, assume that the battery system is rectangle, with the cross-sectional area of $A$ and the length of $L$. The deceleration of the vehicle, as the battery system absorbs energy, can be estimated as $a=P A / M$. Here, for the sake of simplicity, we assume that the crushing pressure is constant over time, so is the deceleration. Hence, for a battery system with $A=$ $0.3 \mathrm{~m}^{2}$, to keep the deceleration below $60 \mathrm{G}$ [7], $P$ should be lower than $3 \mathrm{MPa}$.

Clearly, the estimations above do not facilitate an accurate analysis. Nevertheless, it validates that there exists a range of crushing pressure, around 1-3 MPa, at which the battery pack can be employed as a protective structural component to absorb vehicle kinetic energy and to keep the 
deceleration relatively low, meeting the requirements of vehicle crashworthiness testing. As a result, a variety of other structural parts of auto-frame may no longer be necessary, leading to a considerable weight reduction. The effective "net" mass of battery system can be taken as the actual battery system mass, $m_{1}$, subtracting the saved mass from auto-frame, $m_{2}$. While due to the constraints of battery chemistry, $m_{1}$ must be relatively high, $\left(m_{1}-m_{2}\right)$ may meet the functional requirement of $\mathrm{EV}$, by using existing or near-future battery chemistry.

Currently, the study on multifunctional EV battery system is still in its early stage. It was proposed that, as cylindrical battery cells are placed in parallel and confined by regular walls $[8,9]$, a disintegrable structure can be formed, which provides sufficient flexibility to protect battery cells in a vehicle collision. A number of studies were performed on battery safety and robustness at the cell level [10-15]. Functional current collector (FCC) [10-12] was developed to isolate the damaged areas in a mechanically abused battery cell, which significantly decreased the heat generation rate. Thermally sensitive binder (TSB) $[13,14]$ was developed to reduce the electronic conductivity once the battery was overheated, and thermal runaway retardant (TRR) [15] was employed to lower the ionic conductivity. The battery cells were typically tested through nail penetration, blunt impact or indentation [10-15]; in such tests, the cell case would largely deform and the active materials were internally shorted. In addition, computer simulation at the vehicle level [16] has demonstrated that strategic placement of battery pack could reduce the impact forces on occupants and minimize the damages of battery cells. However, little study has been conducted on the level of battery module. To fully take advantage of the multifunctional design of battery cells in $\mathrm{EV}$, the structure of battery module needs to be reinvestigated.

It is hypothesized that a high deformability of battery module would be beneficial. In the current research, we focus on designing and testing individual battery module. Since battery cells are expensive and contain flammable electrolyte, mechanical loading on battery module will be carried by the energy absorbing elements, separate from the battery cells.

\section{Experiment and computer simulation}

A deformable, butterfly-shaped battery module structure was designed, as depicted in Fig. 1. Prismatic aluminum cells were employed as analogs to hard battery cells, with the height, width, and thickness being 25.4, 25.4, and $4.76 \mathrm{~mm}$, respectively. One end of the cell was tapered at an angle of $45^{\circ}$. The tip of the tapered edge was rounded, and the length of the ramp section was $4.76 \mathrm{~mm}$. The opposite end of the cell was flat, and the two surfaces were respectively connected to two McMaster-Carr 1603A23 brass surface-mount hinges, using McMaster-Carr 91500A086 bolts and McMaster-Carr 91841A003 nuts. The bolt size was 2-56; the hinge was $25.4 \mathrm{~mm}$ wide and $0.5 \mathrm{~mm}$ thick, with the leaf height of $25.4 \mathrm{~mm}$.

Each model battery module consisted of four cells and four hinges. The upper and bottom hinges were fully folded; the left and right hinges were fully open. Thus, the four cells were aligned along the axial direction. They were mounted vertically on a McMaster-Carr 8982K39 aluminum angle, which served as the support. Another angle was inserted upside down on the top, as the guide. The width, the arm length, and the thickness of the angles were $25.4,25.4$, and $0.5 \mathrm{~mm}$, respectively. The initial configuration of the module was left-right and top-town symmetric.

Two McMaster-Carr 6100K149 steel tubes, with the length, the outer diameter, and the wall thickness of 76.2, 7.14 , and $0.127 \mathrm{~mm}$, respectively, were employed as energy absorption elements (EAE). They were attached to the two lateral sides of the hinged cells by $3 \mathrm{M}$ DP110 adhesive. (a)

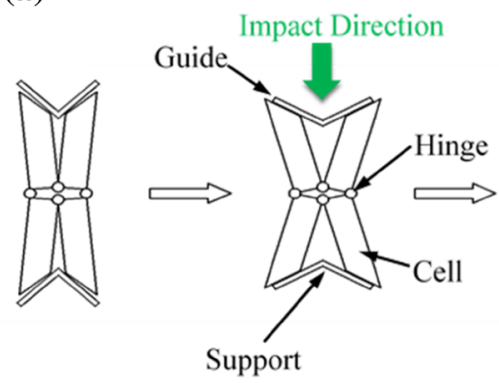

(b)

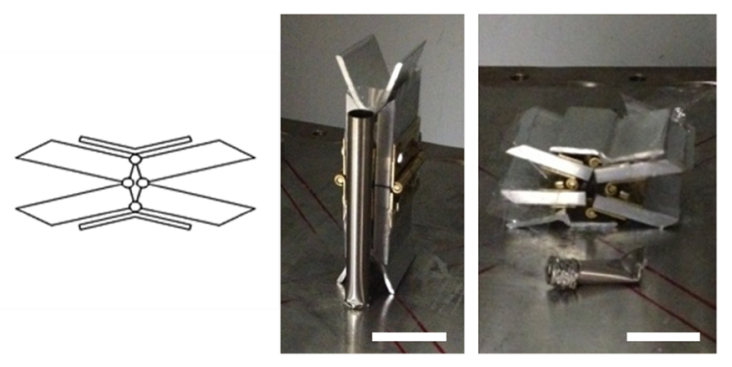

Fig. 1 a Schematic of butterfly-shaped battery module: before (left), during (middle), and after (right) deformation. b Photos of a testing sample: before (left) and after (right) impact; the scale bars indicate $20 \mathrm{~mm}$ 
The module was placed on a large flat 6.35 -mm-thick steel plate, which was firmly mounted on the base holder of an Instron Ceast-9350 drop tower. A 12.7-mm-thick 101.6mm-diameter circular hardened-steel impact head was launched onto the angle guide, with the impact velocity of $v=7.7 \mathrm{~m} / \mathrm{s}$. The total drop mass was $m=3.65 \mathrm{~kg}$. The deceleration was measured by an accelerometer embedded in the impact head; the drop-mass displacement was simultaneously recorded by a linear variable differential transformer (LVDT). Altogether four sets of modules were tested. Their behaviors were quite similar.

Finite element analysis (FEA) was conducted using ABAQUS with explicit package. The FEA model is shown in Fig. 2a, identical to the experimental setup. Linear elastoplastic material models were employed. For the EAE elements, the Young's modulus $E_{\mathrm{Fe}}=200 \mathrm{GPa}$, the yield stress $\sigma_{\mathrm{Y}-\mathrm{Fe}}=500 \mathrm{MPa}$, the Poisson's ratio $v_{\mathrm{Fe}}=0.33$, and the mass density $\rho_{\mathrm{Fe}}=7800 \mathrm{~kg} / \mathrm{m}^{3}$. For the cells, $E_{\mathrm{Al}}=70 \mathrm{GPa}$, $\sigma_{\mathrm{Y}-\mathrm{Al}}=300 \mathrm{MPa}, v_{\mathrm{Al}}=0.33$, and $\rho_{\mathrm{Al}}=2700 \mathrm{~kg} / \mathrm{m}^{3}$. Friction coefficient was set to $\mu=0.3$. Mesh convergence study was carried out to ensure appropriate mesh density.

\section{Results and discussion}

Currently, the energy storage of EV relies on lithium (Li) ion batteries, which have the highest specific energy per $\mathrm{kg}$ and the lowest specific cost per $\mathrm{kWh}$, compared with lead acid batteries, nickel-metal hydride (NiMH) batteries, and double-layer and pseudo-supercapacitors [17]. Lithium-ion battery cells contain electrolytes based on highly flammable organic solutions such as dimethyl carbonate (DMC), diethyl carbonate (DEC), and ethyl methyl carbonate (EMC), since Li phase is incompatible with aqueous solutions [18]. The organic solvents are volatile, having relatively low boiling points around $110{ }^{\circ} \mathrm{C}$ and low flash points below room temperature; their combustion heats are quite high, around $1 \mathrm{~kJ} / \mathrm{g}$ [19], lower than yet on the same scale as that of gasoline [20]. Thus, if the battery cells largely deform and the electrolyte solutions spill out, tough challenges would be imposed to system safety. To be conservative, in the current research, the high deformability of battery module is achieved by using connection hinges; the battery cells behave as "rigid" parts.

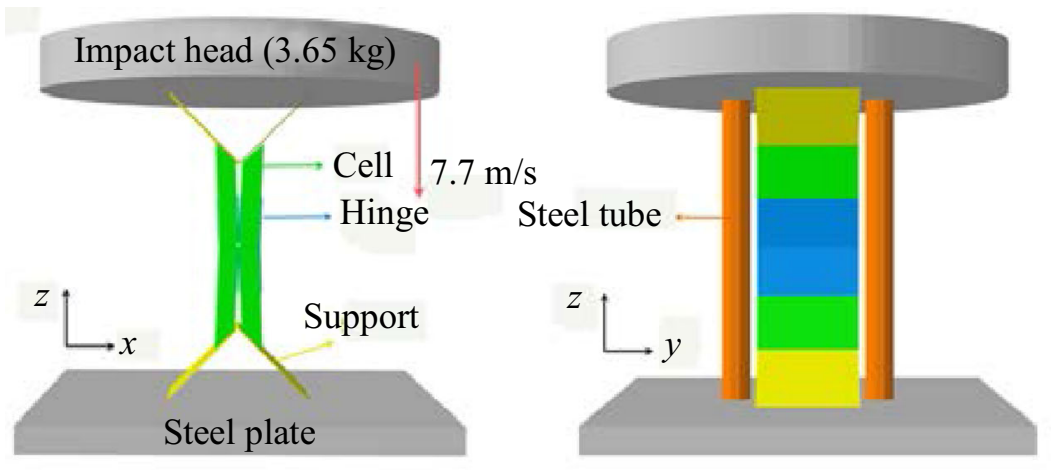

(a)
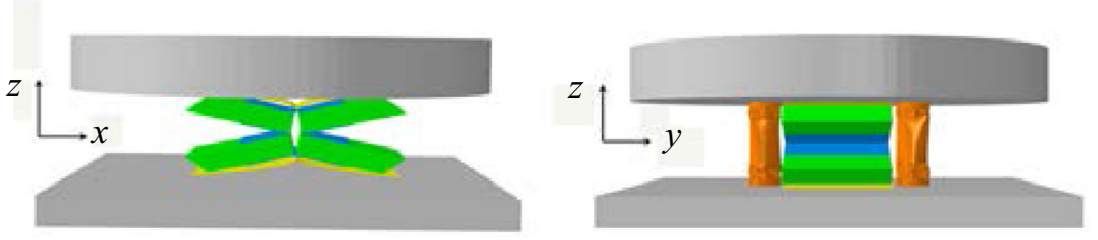

(b)

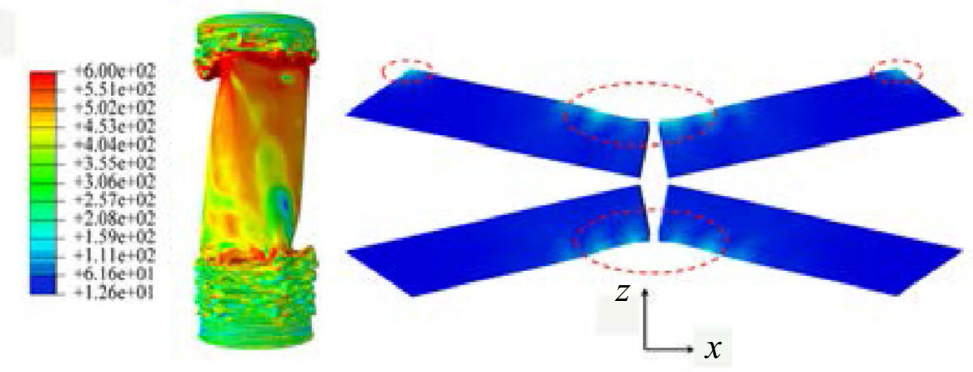

(c)

Fig. 2 Computer simulation of battery module a before and $\mathbf{b}$ after impact; $\mathbf{c}$ stress distribution in the battery module at $10 \mathrm{~ms}$ during impact 
The initial configuration of the battery module is fully folded. Upon the dynamic compressive loading from the drop mass, the tapered cell edge and the impact guide trigger a smooth self-unfolding, aided by the angle support from the bottom. The cells are freely jointed by the hinges, and the motion is quite resistance free and robust. Even when the angle guide and support are damaged, once the self-unfolding begins it would continue until the cell assembly is flattened. During the deformation process, the cells are designed to be "loading-free", as long as the frictions are small. As shown in Fig. 2b, during impact, the stress level in the cells is quite low; stress concentration occurs around the hinges and the top of upper cells. Most of the loadings are carried by the EAE. Therefore, the cell assembly can reach a high deformability, while the cell damage is trivial. According to necessity, additional protection components may be included in the bottom section of the module; hence, when the module self-unfolding completes, direct impact on cell surfaces is minimized.

The favorable working pressure of multifunctional battery system, as approximately analyzed in the introductory section, is 1-3 MPa. Because the volume of battery modules is only a fraction of that of the battery pack [9] and also because higher working pressure leads to better energy absorption capacity, the crushing pressure at the module level should be close to the high end, i.e., 3-5 MPa. The resistance to external loading is mainly offered by EAE, separately assembled next to the battery cells. The modularized structure enables independent adjustment of the performance of individual battery cells and the mechanical responses of module. The EAE is lightweight and highly deformable. As their wall thickness and size are controlled, the buckling pressure can be tailored in a broad range. As shown in Figs. 2c and 3a, shortly after the drop mass impacts the cell assembly, in less than $1 \mathrm{~ms}$, the tube buckling takes place, resulting in a buckling plateau in the stress-strain curve. Figure 3 a shows the profiles of engineering stress, $\sigma=F / A_{0}$, and engineering strain, $\varepsilon=\Delta H / H_{0}$, where $F=m a$ is the impact force, $a$ is the deceleration of drop mass, $A_{0}$ is the initial cross-sectional area, $\Delta H$ is the system deformation, and $H_{0}$ is the initial height. As the EAE is compressed, elastic energy is stored by the tube wall, and when it exceeds the limit of structural stability, wrinkles would form and propagate along the axial direction. The buckling pressure, $P$, is relatively constant as the wrinkles develop.

Figure $3 \mathrm{a}$ indicates that as the engineering strain is $\sim 5 \%$, the buckling pressure reaches $2 \mathrm{MPa}$, and it varies around 2-5 MPa until the engineering strain exceeds $\sim 60 \%$, close to the desired level. The maximum strain is around $70 \%$, mainly determined by the volume fraction of the hollow space, measured by $\tilde{t}=t / R$, with $t$ being the (a)

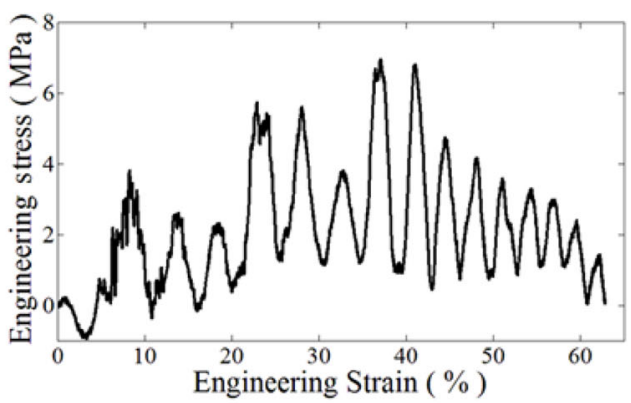

(b)

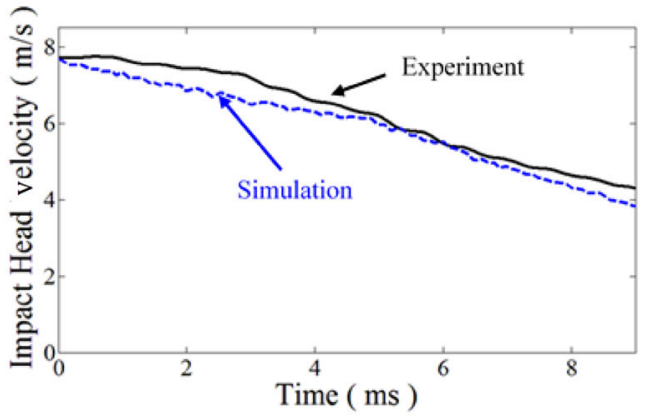

(c)

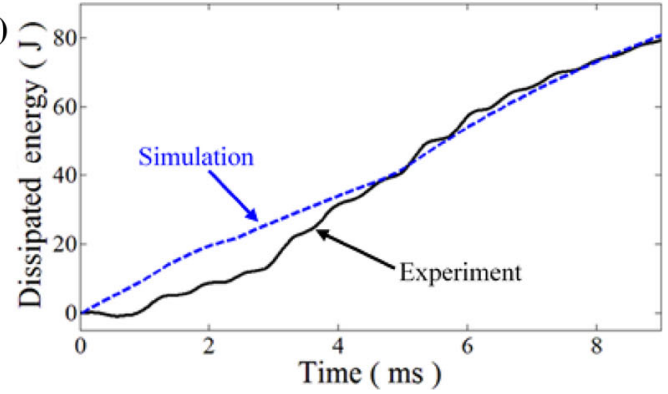

Fig. 3 Typical impact testing and computer simulation results: a the dynamic stress-strain relation; $\mathbf{b}$ the drop-mass velocity; and $\mathbf{c}$ the absorbed energy

wall thickness and $R$ the radius. According to the $\Pi$ theorem [21], the buckling pressure $(P)$ is a functional of $E$, $H_{0}, R$, and $\widetilde{t}$, with $E$ being the Young's modulus; thus, $P / E$ $=f(\rho, \widetilde{t})$, where $\rho=H_{0} / R$ is the aspect ratio and $f$ is a certain function. By adjusting $E, \rho$, and $\widetilde{t}$, the working pressure of EAE can be varied to meet different functional requirements. As a new wrinkle is nucleated, the pressure would drop; as the wrinkle is folded, the pressure would increase. Therefore, the buckling plateau of a smooth tube is inevitably jerky. If needed, the buckling plateau can be smoothened by using tubes of crimped walls.

Although the buckling pressure fluctuates, because the fluctuation frequency is high, it does not have any pronounced influence on the drop-mass velocity, as shown in Fig. 3b. After the initial setting period of a couple of ms, the drop-mass velocity decreases nearly linearly, with the deceleration of $\sim 500 \mathrm{~m} / \mathrm{s}^{2}$, or $\sim 50 \mathrm{G}$. The simulation results agree well with the experiment. The relatively 
constant velocity changing rate suggests that the protective cell module works smoothly.

The absorbed energy is shown in Fig. 3c. Due to the reduction in drop-mass velocity, the energy dissipation rate keeps descending. After the initial setting period, most of the kinetic energy is absorbed in the following $\sim 5 \mathrm{~ms}$, after which the deformation of the cell assembly becomes less intensive.

\section{Concluding remarks}

Butterfly-shaped self-unfolding battery module is designed and tested. The goal is to achieve a controlled resistance and a large deformability, with the impact loading on battery cells being minimized. The battery cells are freely jointed by a set of hinges and initially fully folded. Upon a compressive loading, the hinges, aided by a guide from the top and an angle support from the bottom, help unfold the cells. The resistance is offered by a set of energy absorption elements (EAE) in parallel to the battery cells. The resistance and the cell motion are decoupled, so as to independently adjust the performance of battery cells and the mechanical responses of module. The resistance pressure offered by the cell assembly is a few MPa; the deformability is more than $60 \%$. The relatively large fluctuation of resistance pressure does not have much detrimental effect on the smooth reduction of drop-mass velocity. During impact, most of the kinetic energy is absorbed in a few ms after the initial setting period. Such a multifunctional battery module may be employed as structural components in electric vehicles, so as to lower the overall vehicle mass and increase the drive range.

Acknowledgements This research was supported by the Advanced Research Projects Agency-Energy (ARPA-E) under Grant No. DEAR0000396, for which we are grateful to Dr. Ping Liu, Dr. John Lemmon, Dr. Grigorii Soloveichik, Dr. Chris Atkinson and Dr. Dawson Cagle.

Open Access This article is distributed under the terms of the Creative Commons Attribution 4.0 International License (http:// creativecommons.org/licenses/by/4.0/), which permits unrestricted use, distribution, and reproduction in any medium, provided you give appropriate credit to the original author(s) and the source, provide a link to the Creative Commons license, and indicate if changes were made.

\section{References}

1. Guarnieri M (2012) Looking back to electric cars. In: HISTory of ELectro-technology conference (HISTELCON), 2012 Third IEEE. IEEE, pp 1-6
2. Howell D (2012) Battery status and cost reduction prospects. In: EV everywhere grand challenge battery workshop

3. Young K, Wang C, Wang LY, Strunz K (2013) Electric vehicle battery technologies. In: Garcia-Valle R, Lopes JAP (eds) Electric vehicle integration into modern power networks. Springer, New York, pp 15-56

4. Srinivasan V (2008) Batteries for vehicular applications. In: Hafemeister D, Levine M, Schwartz P (eds) Physics of sustainable energy: using energy efficiently and producing it renewably, AIP conference proceedings 1044. Berkeley, USA, March 1-2, pp 283-296

5. Laboratory test procedure for new car assessment program frontal impact testing. Federal Highway Administration, U.S. Department of Transportation

6. Markel T, Tataria HS, Howell D (2009) Battery requirements for plug-in hybrid electric vehicles-analysis and rationale. National Renewable Energy Laboratory, Golden

7. Mackay M (1997) A review of the biomechanics of impacts in road accidents. In: Ambrósio JA, Pereira MFS, da Silva FP (eds) Crashworthiness of transportation systems: structural impact and occupant protection. Springer, Netherlands, pp 115-138

8. Ginsberg SD (2010) Battery pack. Publication number: EP2418709 A1

9. Nelson PA, Bloom KGI, Dees DW (2011) Modeling the performance and cost of lithium-ion batteries for electric-drive vehicles (No. ANL-11/32). Argonne National Laboratory, Lemont

10. Wang M, Le AV, Noelle DJ, Shi Y, Meng YS, Qiao Y (2017) Internal-short-mitigating current collector for lithium-ion battery. J Power Sources 349:84-93

11. Wang M, Le AV, Shi Y, Noelle DJ, Qiao Y (2017) Heterogeneous current collector in lithium-ion battery for thermal-runaway mitigation. Appl Phys Lett 110:083902

12. Wang M, Le AV, Shi Y, Noelle DJ, Wu D, Fan J, Lu W, Qiao Y (2017) Sigmoidal current collector for lithium-ion battery. J Appl Phys 121:015303

13. Wang M, Le AV, Shi Y, Noelle DJ, Yoon H, Zhang M, Meng Y, Qiao Y (2017) Effects of angular fillers on thermal runaway of lithium-ion battery. J Mater Sci Technol 32:1117-1121

14. Le AV, Wang M, Noelle DJ, Shi Y, Yoon H, Zhang M, Meng YS, Qiao Y (2017) Effects of macromolecular configuration of thermally sensitive binder in lithium-ion battery. J Appl Polym Sci 2017:45078

15. Shi Y, Noelle DJ, Wang M, Le AV, Yoon H, Zhang M, Meng YS, Fan J, Wu D, Qiao Y (2017) Mitigating thermal runaway of lithium-ion battery through electrolyte displacement. Appl Phys Lett 110:063902

16. Hao F, Lu X, Qiao Y, Chen X (2017) Crashworthiness analysis of electric vehicle with energy-absorbing battery modules. ASME J Eng Mater Technol 139:021022

17. Winter M, Brodd RJ (2004) What are batteries, fuel cells, and supercapacitors? Chem Rev 104(10):4245-4270

18. Aurbach D, Talyosef Y, Markovsky B, Markevich E, Zinigrad E, Asraf L, Kim HJ (2004) Design of electrolyte solutions for Li and Li-ion batteries: a review. Electrochim Acta 50(2):247-254

19. Wang Q, Ping P, Zhao X, Chu G, Sun J, Chen C (2012) Thermal runaway caused fire and explosion of lithium ion battery. J Power Sources 208:210-224

20. Heating values of hydrogen and fuels. Hydrogen Analysis Resource Center, U.S. Department of Energy

21. Lu G, Yu TX (2003) Energy absorption of structures and materials. Elsevier, Amsterdam 